\title{
Critical Factors Influencing the Performance of E-Business in SMEs
}

\author{
${ }^{1}$ Soheil Mojtabaei Motlagh, ${ }^{2}$ Mohammad Ali Jabbari Sabegh \\ ${ }^{12}$ (Graduate School of Management, Multimedia University, Malaysia)
}

\begin{abstract}
E-business technologies have significantly affected business processes of companies. As a result, it is critical for organizations to have an effective and efficient e-business performance, particularly, for small and medium sized enterprises due to their lack of financial and human resources. The purpose of this paper is to study the factors influencing the performance of e-business in Malaysian small and medium sized enterprises. Quantitative method was used for this study and data were collected through survey questionnaire from managers working in SMEs performing in Malaysia. E-communication, e-intelligence, e-collaboration, knowledge sharing, IT employee, and External IT are the examined factors. All six hypotheses were supported by results of the study. Knowledge and expertise of IT employees and external IT were reported to be the most influential aspects on the performance of e-business in SMEs. Theories used in this study include resourcebased view, knowledge-based theory, and competence-based theory.
\end{abstract}

Keywords: e-business capabilities, e-business performance, knowledge sharing, IT outsourcing, SME.

\section{Introduction}

The way of doing business by companies has been influenced by e-business technologies adoption. Ebusiness system has been defined as "any form of commercial or administrative transaction or information exchange that an organization makes available over the internet" [1]. Companies have increased their value chain efficiency and level of competition by using these technologies intensively. Moreover, the effectiveness of the communication channel between company and customers as well as company and its partners has been increased significantly [2].

The importance of e-business implementation is more highlighted when it comes to small and medium sized enterprises. Because of the lack of human and financial resources, it is almost impossible for SMEs to compete with large companies; by adoption of e-business technologies, they will be able to expand their markets in an international context, and support their customers all over the globe. However, it is not only about adoption of e-business, but it is also about effectiveness and efficiency.

There are several researches focusing on the factors influencing the adoption of e-business. However, it should be noticed that a successful company should not only focus on the adoption stage, but it should also consider factors which help improve the performance of e-business. In other words, only adoption of a technology does not guarantee the success of the business. There are very few researches about how to enhance the performance of e-businesses in SMEs and, to our knowledge, there are almost no researches conducted in this area concentrating on Malaysian SMEs. The focus of this study is on the factors affecting the performance of e-business.

Application of e-business can create internal efficiency as well as external coordination throughout changes in inter- or intra-organizational integrative processes [3]. However, e-business is a type of innovation that is likely to reduce performance initially, but promises greater potential in long-term. Adoption of e-business technologies cannot guarantee a sustainable competitive advantage because they are open and accessible to competitors [4]. There have been numerous researches on the effect of information technology on firm performance ranging from impact measurement, to the necessary conditions to understand these impacts [5].

Economic effects do not originate from IT investments straightforwardly, but throughout the value generated by its interaction with the firm's complementary assets. Firms will be able to exploit complementary assets and attain benefits of effectiveness and efficiency only if they integrate e-business with its strategic direction [4].

\section{Theoretical background and hypothesis development}

There are varieties of factors which can influence the performance of e-business; e-communication, eintelligence, and e-collaboration are of those factors which are categorized as e-business capabilities [6]. In the resource-based view, a firm is conceptualized as a collection of dynamic capabilities and resources that are essentially valuable; therefore, it is suggested that the strategy of the company should basically be delineated by its unique capabilities and resources $[7,8]$. In the context of e-business, e-business capabilities themselves are seen as a "source of competitive advantage" in this point of view [9]. 
E-communication refers to the promulgation of the company, its products or services, including online catalogs, brochureware, and other sorts of internet uses such as intranets and extranets, and web pages designed to communicate with consumers and employees [10]. E-intelligence which is also known as e-business intelligence is another factor that may affect e-business performance. The breadth and nature of information accessible on the internet enable companies to scrutinize their commercial, technological, and competitive environment in order to identify means and methods to enhance their processes and decision making ability, and search for new product-market opportunities [11]. E-collaboration as another factor which can be used in ebusiness includes integration and sharing information throughout the internet and extranets in order to link the company with its downstream and upstream business partners [6]. By doing so, stakeholders in the same industry with common objectives will be able to collaborate in design, production, development, and management of products or services at different phases of their life-cycle [12]. Thus, we introduce the following hypotheses:

H1: E-communication is positively associated with e-business performance.

H2: E-intelligence is positively associated with e-business performance.

H3: E-collaboration is positively associated with performance of e-business.

The knowledge-based theory [13] contends that to achieve competitive advantage, knowledge should coordinate at organizational level. A central part of "the knowledge-based theory" is knowledge sharing because the main reason for a company to survive is being greatly capable of transferring and integrating several knowledge streams and also applying that knowledge to tasks [14]. Knowledge sharing has been defined as "the business processes that distribute knowledge among all individuals participating in process activities" [1]. According to the previous studies, effectiveness of IS in the organizational context emphasizes on the knowledge sharing culture as the key organizational provision for successful management and utilization of knowledge [15]. It has been suggested that openness to knowledge sharing is essential for enhancing innovative performance [16]. Moreover, in the e-business, knowledge sharing plays an important role in innovation processes $[17,18]$. Therefore, knowledge sharing is expected to be associated with performance of e-business. Thus, the following hypothesis is introduced by this study:

H4: Knowledge sharing is positively associated with the performance of e-business.

According to the competence-based theory, the key source of a company's sustainable competitive advantage is its distinctive capabilities [13]. Distinctive capabilities include employees' and, specially, founders' knowledge and skills [19] and also innovation capability throughout the greater management capabilities [20].

Knowledge about IT plays a significant role in new technology adoption and increases the degree of a company's technology adoption and performance [21]. Companies without enough IT expertise may not be aware of new technologies and it may affect the performance of their business. Moreover, a company with ebusiness specialists has a higher possibility to take up IT innovations as it could develop its own website or could use specific technologies in order to manage the value chain better [1].

Individuals with greater work experience and higher educational level are supposed to have more specialized knowledge than others [19]. Specialized IT staff is considered as a source for large enterprises to rise their IT expertise, which in most cases, is not possible for SMEs because of their lack of resources.

Outsourcing is another approach to enhance e-business performance for companies which have lack of expertise and other resources or don't want to spend their internal resources on this part. Indeed, outsourcing is becoming a more popular approach among companies, and they prefer to pursue IT technologies using IT supporting services of other firms which offer these kinds of services [22, 23]. Generally, the main reason for a company to outsource a specific function is the lack of human resources and expertise for it [24, 25, 26]. External partners provide a particular knowledge which is required by different ICTs. Outsourcing is done by SMEs frequently [27] because it overcomes the problem of intellectual resources limitation. Outsourcing may be an effective solution to improve the performance of e-business as it may suffer from the lack of expertise and high initial costs. Therefore, the following hypotheses are introduced by this study:

H5: IT employee is positively associated with e-business performance.

H6: External IT is positively associated with the performance of e-business.

\section{Research method}

Based on the existing literature and the constructs described above, a survey questionnaire was designed to collect data from randomly selected samples from the population. The population of this research consists of managers working in small and medium sized enterprises (SMEs) which have already adopted ebusiness initiatives.

From 700 distributed survey questionnaires, 191questionnaiers were returned and among them, 12 questionnaires were rejected because they included items with more than one answer or unanswered items, thus, considered as rudimentary and invalid data. Collected data were analyzed by Statistical Package for Social Science (SPSS) software. Frequency analysis and regression analysis were used to examine the collected data. Furthermore, reliability test was done to test the extent of the variables' reliability. 


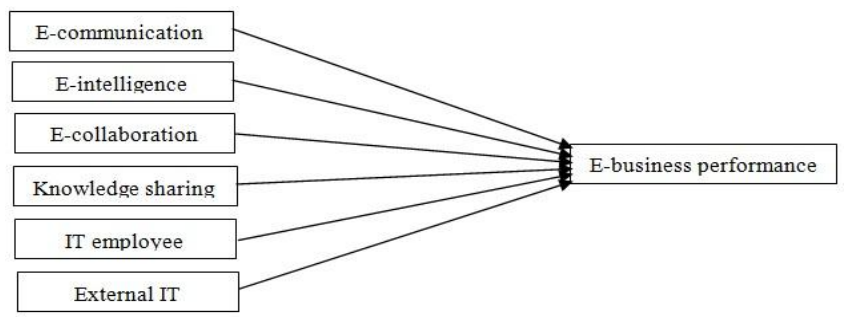

Figure 1: Conceptual model

\section{Data analysis and results}

Our respondents are the managers of small and medium sized enterprises. From 179 respondents, 62 percent are males and 38 percent are females. SMEs which we collected data from include SMEs that offer services, products, or both services and products for their customers. 29.9 percent of entire respondents are from service organizations, 23.6 percent are from SMEs which offer products, and 46.5 percent are from SMEs that offer both products and services. Among selected companies $9.7 \%$ of them have less than 10 employees, $27.1 \%$ of them have between 10 and 30 employees, $7.6 \%$ have between 30 and 50 employees, $7.6 \%$ of them have between 50 and 70 employees, $4.9 \%$ of them have between 70 and 100 employees, and $43.1 \%$ have between 100 and 150 employees.

\subsection{Reliability Test}

Reliability of each construct was tested through Cronbach's alpha. A value of 6 to 7 for Cronbach's alpha is considered as a proper degree of reliability, and values above 7 are considered as a good degree of reliability [28]. Therefore, we can contend that all constructs obtained a good level of reliability as the Cronbach's alpha for knowledge sharing is 0.829 , for e-collaboration is 0.806 , for e-communication is 0.805 , for e-intelligence is 0.833 , for IT employee is 0.769 , for external IT is 0.871 , and for e-business performance is 0.821 . Thus, these measures are relevant and can be used for correlations and regressions tests. Table1 represents the results of the reliability test.

\begin{tabular}{lcc}
\multicolumn{3}{c}{ Table 1: Reliability Test } \\
\hline Constructs & $\begin{array}{c}\text { Cronbach's } \\
\text { Alpha }\end{array}$ & $\begin{array}{c}\text { Number of } \\
\text { Items }\end{array}$ \\
\hline E-Communication & 0.805 & 3 \\
E-Intelligence & 0.833 & 3 \\
E-Collaboration & 0.806 & 4 \\
Knowledge Sharing & 0.829 & 4 \\
IT employee & 0.769 & 4 \\
External IT & 0.871 & 3 \\
E-Business Performance & 0.821 & 3 \\
\hline
\end{tabular}

\subsection{Hypothesis testing}

Based on the regression analysis, results of correlations, coefficients, mean, and standard deviation of all constructs are considered. Table 2 present the results of the regression analysis of all variables of this research.

According to the results, average response rate for all variables are between 3.5 and 4.0. Knowledge sharing with mean equal to 3.608 got the lowest rate and e-communication with the mean 3.991 obtained the highest average rate from respondents. Standard deviations are around 0.5 , but e-intelligence has the highest standard deviation equal to 0.568 and IT employee with 0.456 have the lowest standard deviation.

Table 2: Mean, standard deviation and correlation results

\begin{tabular}{lccccccccc}
\hline & Mean & $\begin{array}{c}\text { Std. } \\
\text { Deviation }\end{array}$ & 1 & 2 & 3 & 4 & 5 & 6 & 7 \\
\hline $\begin{array}{l}\text { E-Business } \\
\text { Performance }\end{array}$ & 3.795 & .504 & 1.00 & & & & & & \\
E-Communication & 3.991 & .506 & 0.306 & 1.00 & & & & & \\
$\begin{array}{l}\text { E-Intelligence } \\
\text { E-Collaboration }\end{array}$ & 3.648 & .568 & 0.473 & 0.372 & 1.00 & & & & \\
Knowledge & 3.710 & .535 & 0.351 & 0.612 & 0.550 & 1.00 & & & \\
Sharing & 3.608 & .489 & 0.278 & 0.384 & 0.578 & 0.633 & 1.00 & & \\
IT employee & 3.773 & .456 & 0.484 & 0.541 & 0.551 & 0.571 & 0.444 & 1.00 & \\
External IT & 3.778 & .526 & 0.821 & 0.269 & 0.491 & 0.373 & 0.271 & 0.522 & 1.00 \\
\hline
\end{tabular}

In terms of associations among the independent variables, there are some significant results. Variables are positively related to each other while there is significant correlation between knowledge sharing and e- 
collaboration (0.633). E-intelligence is positively correlated with knowledge sharing and e-collaboration $(0.578$ and 0.550$)$. IT employee has positive relationship with e-collaboration, e-communication and e-intelligence $(0.571,0.541$, and 0.551$)$. Meanwhile, IT employee also is significantly correlated with external IT $(0.552)$.

The constructs used in this study were developed from the review of previous studies and discussed literature in previous section. To analyze the effect of independent variables on e-business performance and in order to test hypotheses, regression analysis was used. Obtained results reveal that e-communication $(\beta=0.306$, $P<0.05)$ has significant effect on e-business performance. E-intelligence $(\beta=0.473, P<0.05)$, e-collaboration $(\beta=0.35, \mathrm{P}<0.05)$, knowledge sharing $(\beta=0.278, \mathrm{P}<0.05)$, IT employee $(\beta=0.484, \mathrm{P}<0.05)$, and external IT $(\beta=0.82, p<0.05)$ have positive effect on performance of e-business at $5 \%$ confidence level respectively.

According to the results, communicating with customers as well as promoting the firm's products and services through extranets and internet has a positive influence on the performance of e-business. Thus, we accept H1. Moreover, relationship between e-intelligence and e-business performance reveals that companies can improve their procedures and decision making ability through analyzing their market environment using the information accessible on the internet; therefore, we accept H2. In addition, it was found that using extranets and internet enables companies to be linked to their business partners, and integrate and share their information together. As a result, we accept $\mathrm{H} 3$.

Furthermore, results of the data analysis indicate a positive relationship between knowledge sharing and the performance of e-business. Accordingly, we accept H4. Additionally, knowledge and expertise of IT employees and also, using outsourcing IT services were reported to affect e-business performance positively. Thus, we accept H5 and H6.

\section{Discussion and conclusion}

This study aims to identify the factors affecting the performance of e-business as well as the extent of their influence. While there are many researches on the adoption stage of e-business, there are very few studies focused on e-business performance, especially in the context of small and medium sized enterprises.

According to the results, knowledge sharing has the lowest degree of influence on performance of ebusiness compared to other factors. This might be as a result of the fact that there are many individuals who do not tend to share their knowledge and experience with their colleagues in their work place in order to exploit it as their specialty to be promoted. Furthermore, the results of the data analysis reported that e-communication, ecollaboration, and e-intelligence affect e-business performance positively. E-communication facilitates the interaction between firms and their customers, and companies will be able to have a better relationship with them. By using e- intelligence, companies can analyze their market environment in order to improve their procedures and decision making ability as well as finding opportunities in new markets. In order to have a better performance, firms can share necessary information with their upstream and downstream business partners through extranets and internet; therefore, they will be able to collaborate in different stages of the business (ecollaboration).

Moreover, findings from analysis of data reveal that among the examined factors, external IT has the greatest influence on the performance of e-business in SMEs. Outsourcing is a common approach among small and medium sized firms because of their lack of resources. Knowledge and expertise of IS employees is the second most influential aspect in e-business performance. Comparing the availability of the resources in small firms and medium firms, it seems that outsourcing IT services should happen more in small companies than in medium firms. In a similar vein, hiring IT experts and specialists is supposed to happen more in medium companies than in small firms; however, it cannot be asserted by the findings of this research because the effect of the SME size has not been tested. Nevertheless, our findings suggest that the knowledge and expertise of IS employees and outsourcing IT services are very important factors for e-business performance.

It is recognized that all the variables which are analyzed in this research have positive effect on ebusiness performance while outsourcing has the most significant influence. Using external IT resources provide ability for SMEs to cover their lack of knowledge and expertise in e-business activities and accordingly, increase their performance. Compared to other factors, knowledge and skills of IT employees is the next significant factor in e-business performance. Findings also signify that knowledge sharing has the lowest influence on e-business performance. Based on correlation analysis, knowledge sharing significantly correlates with e-intelligence and e-collaboration, thus knowledge sharing and willingness to share information would be increased by improving e-collaboration capabilities and e-intelligence.

\subsection{Limitations and future research}

There are three limitations for this study. First, because data for this research were collected from managers working in Malaysian SMEs, findings may not be applicable for SMEs performing in other countries due to the possible cultural differences. Second, this study did not make any classification for SMEs and therefore, the extent of the effects in some of the aspects might be different according to the size or type of the 
industry. In addition, the results for the factors which are related to technology can be changed over time because of the fast improvements and innovations in area.

Finally, future studies can examine the impact of the mentioned factors in this study on performance of e-business classified by SME size; moreover, the performance of e-business can be varied based on the type of the industry in which an SME performs in, thus it can also be applied to the future researches.

\section{References:}

[1] Lin Hsiu-Fen, Lee Gwo-Guang (2005), Impact of organizational learning and knowledge management factors on e-business adoption, Management Decision, Vol. 43 No. 2, pp. 171-188.

[2] Tapp, A. and Hughes, T. (2004), New technology and the changing role of marketing, Marketing Intelligence \& Planning, Vol. 22 No. 3, pp. 284-96.

[3] Unda F. Edelman, Candida G. Brush, and Tatiana S. (2002), The impact of human and organizational resources, Journal of small business and enterprise development, Vol. 20, pp. 236-244.

[4] Ye M. and Jiang Y. (2008), Analyzing the Impact of Organizational Factors on Performance of E-business, IEEE.

[5] Rockart, J. and Scott Morton, M.S. (1984), Implications of changes in information technology for corporate strategy, Interfaces, Vol. 14, pp. 84-95.

[6] Raymond, L., Bergeron, F., (2008), Enabling the business strategy of SMEs through e-business capabilities: A strategic alignment perspective, Industrial Management \& Data Systems, Vol. 108 No. 5, pp. 577-595.

[7] Barney, J. (1991), Firm resources and sustained competitive advantage, Journal of Management, Vol. 17 No.1, pp. 99-120.

[8] Teece, D., Pisano, G. and Shuen, A. (1997), Dynamic capabilities and strategic management, Strategic Management Journal, Vol. 18 No. 7, pp. 509-33.

[9] Bharadwaj, A.S. (2000), A resource-based perspective on information technology capability and firm performance: an empirical investigation, MIS Quarterly, Vol. 24 No. 1, pp. 169-96.

[10] Turban, E., Lee, J., King, D. and Chung, H.M. (2000), Electronic commerce: A Managerial perspective, Printice-hall, Upper Saddle River, NJ.

[11] Hill, J. and Scott, T. (2004), A consideration of the roles of business intelligence and e-business in management and marketing decision making in knowledge-based and high-tech start-ups, Quantitative Market Research: An International Journal, Vol. 7 No. 1 , pp. 48-57.

[12] Cassivi, L., Lefebvre, E., Lefebvre, L.A. and Leger, P-M. (2004), The impact of e-collaboration tools on firms' performance, International Journal of Logistics Management, Vol. 15 No. 1, pp. 91-110.

[13] Grant, R.M. (1996), Toward a knowledge-based theory of the firm, Strategic Management Journal, Vol. 17, winter, special issue, pp. 109-22.

[14] Sherry D. Ryan, John C. Windsor, Bashorat Ibragimova, and Victor R. Prybutok (2010), Organizational practices that Foster Knowledge Sharing: Validation across Distinct National Cultures, The International Journal of an Emerging Transdiscipline, Vol. 13. 6, pp. 610-26.

[15] Damodaran, L. and Olpher, W. (2000), Barriers and facilitators to the use of knowledge management systems, Behaviour and Information Technology, Vol. 19 No. 6, pp. 405-13.

[16] Caloghirou, Y., Kastelli, I. and Tsakanikas, A. (2004), Internal capabilities and external knowledge sources: complements or substitutes for innovation performance, Technovation, Vol. 24 No. 1, pp. 29-39.

[17] Liebowitz, J. (2002), Facilitating innovation through knowledge sharing: a look at the US Naval Surface Warfare Center-Carderock division, Journal of Computer Information Systems, Vol. 42 No. 5, pp. 1-6.

[18] Nah, F., Siau, K., Tian, Y. and Ling, M. (2002), Knowledge management mechanisms in e-commerce: a study of online retailing and auction sites, Journal of Computer Information Systems, Vol. 42 No. 5, pp. 119-28.

[19] Colombo, M.G. and Grilli, L. (2010), On growth drivers of high-tech start-ups: exploring the role of founders' human capital and venture capital, Journal of Business Venturing, Vol. 25 No. 6, pp. 610-26.

[20] Merrilees, B., Rundle-Thiele, S. and Lye, A. (2011), Marketing capabilities: antecedents and implications for B2B SME performance, Industrial Marketing Management, Vol. 40 No. 3, pp. 368-75.

[21] Robey, D., Ross, J.W. and Boudreau, M.C. (2002), Learning to implement enterprise systems: an exploratory study of the dialectics of change, Journal of Management Information Systems, Vol. 19 No. 1, pp. 17-46.

[22] Ramdani, B., Kawalek, P. and Lorenzo, O. (2009), Predicting SMEs' adoption of enterprise systems, Journal of Enterprise Information Management, Vol. 22 Nos 1/2, pp. 10-24.

[23] Bahli, B. and Rivard, S. (2003), The information technology outsourcing risk: a transaction cost and agency theory-based perspective, Journal of Information Technology, Vol. 18 No. 3, pp. 211-21.

[24] Green, M.E. (2000), Beware and prepare: the government workforce of the future, Public Personnel Management, Vol. 29 No. 4 , pp. 435-44.

[25] Wright, L. (2001), Market viewpoint: outsourcing is a no-claims bonus, Insurance Brokers' Monthly \& Insurance Adviser, Vol. 51 No.1, pp.12-15.

[26] Hong, W. and Zhu, K. (2006), Migrating to internet-based e-commerce: factors affecting e-commerce adoption and migration at the firm level, Information \& Management, Vol. 43 No. 2, pp. 204-21.

[27] Gabrielli, V. and Balboni, B. (2010), SME practice towards integrated marketing communications, Marketing Intelligence \& Planning, Vol. 28 No. 3, pp. 275-90.

[28] Sekaran, U. (2003), Research methods for business. A skill building approach, New York: Wiley. 